\title{
Mineração
}

\section{Cominuição a seco de mesclas de quartzo e dolomita}

\section{Dry comminution of quartz and dolomite mixtures}

\author{
Germano Mendes Rosa \\ Instituto Federal Minas Gerais - IFMG \\ Campus Congonhas \\ Coordenadoria de Produção Industrial e \\ Mineração \\ Mestrando do PPGEM/UFOP \\ germano_rosa@yahoo.com.br \\ José Aurélio Medeiros da Luz \\ Universidade Federal de Ouro Preto - UFOP- \\ Escola de Minas \\ Departamento de Engenharia de Minas - DEMIN \\ jaurelio@demin.ufop.br
}

\section{Resumo}

Estudou-se o comportamento dos principais parâmetros da moagem a seco de mesclas binárias em batelada dos minerais dolomita e quartzo. Por meio de vários ensaios físicos com diferentes proporções desses minerais por diferentes ciclos moagem, acompanhou-se a evolução da granulação dos produtos em termos de coeficiente de agudez, $a$, e diâmetro, $d_{50}$, parâmetros da função de distribuição de probabilidades sigmoidal de Hill, a qual foi utilizada para ajustar a nuvem de dados. Os resultados subsidiaram o desenvolvimento de sistema simulador de cominuição baseado em rede neural artificial (do tipo perceptron de multicamada com algoritmo de supervisão e treinamento de retropropagação com momento), a ser objeto de artigo futuro.

Palavras-chave: Cominuição seletiva; moabilidade; redes neurais artificiais.

\begin{abstract}
The behavior of batch grinding of a dry binary mix using dolomite and quartz has been studied. Through several tests with different proportions of these minerals and different grinding cycles, the granular system evolution was observed in terms of sharpness coefficient and mean diameter $d_{50}$. These parameters were fit into the Hill's sigmoidal function of probability distribution to adjust the results. The results were used for the validation of a neural network system (multilayer perceptron-like algorithm), which will be presented in another article.
\end{abstract}

Keywords: Selective comminution, grindability, artificial neural networks.

\section{Introdução}

A separação eficiente entre espécies minerais constituintes de determinado agregado mineralógico, na maioria dos casos, é imprescindível para atingir-se o objetivo final de utilização industrial de uma ou mais dessas espécies minerais, sendo muitas vezes necessário descartarem-se outras espécies consideradas com baixo ou sem nenhum valor agregado (ganga).

Para prover a separação por espécie dos componentes de determinado minério, em processos subsequentes à moagem, é potencialmente desejável que as partículas de espécies distintas apresentem, entre outras características, diferenças na granulação. tais partículas serão exploradas em processos de concentração, como a concentração gravítica, por exemplo.

Por existirem, normalmente, diferenças de moabilidade entre as espécies minerais componentes do minério processado, diferentes distribuições granulométricas dos produtos também podem ser obtidas a partir de uma determinada distribuição de tamanho dos componentes da alimentação, que, por sua vez, são afetados pelos parâmetros de operação na moagem.

Considerando-se necessário liberar e separar duas ou mais espécies minerais de determinado minério, uma moagem eficiente, usualmente, deve prover contraste granulométrico entre essas espécies. Em casos extremos, poder-se-ia efetuar a separação por espécie com, unicamente, 
operação de fracionamento granulométrico, como peneiramento ou classificação em meio fluido.

Para alimentação de mesma granulação para as espécies de um minério binário, observando-se as distribuições das frações granulométricas dos produtos, pode-se verificar, graficamente, que, quanto menor for a área de interseção entre essas curvas, maior seletividade houve na moagem realizada. Exemplo hipotético pode ser visualizado por meio da Figura 1.

Deve-se ter em mente que, mesmo que as duas espécies estejam previamente liberadas, seu contraste granulométrico, na saída, afeta operações ulteriores de separação por espécie. Com diferenças acentuadas na moabilidade dos constituintes da mistu- ra, consegue-se, por vezes, concentração adequada apenas com operação de fracionamento granulométrico (peneiramento ou classificação). Esse contraste está ligado ao afastamento entre os diâmetros medianos das duas espécies e aumenta na medida em que a área hachurada da Figura 1 diminui.

Por outro lado, o processo de moagem caracteriza-se como dos mais dispendiosos numa usina de beneficiamento industrial, devido ao baixo aproveitamento energético e aos altos esforços mecânicos envolvidos (Chaves \& Peres, 1999; Delbony Júnior, 2007; Luz et alii, 2004), justificando, sobremaneira, empenho nesse campo de estudo.

Assim, em princípio, para cada constituição de mescla e configuração do circuito de cominuição, deve haver tempo de residência ótimo, que acarrete a maximização do benefício econômico do empreendimento. Isso justifica estudo criterioso, em especial com ingresso de argumentação econômica, quanto ao ótimo ponto de moagem (custos de cominuição versus ganhos de enriquecimento e recuperação ulteriores).

Como ponto de partida ao estudo da seletividade em moagem de mesclas binárias, esse artigo analisa a evolução dos principais parâmetros relacionados à granulação dos produtos, embasado em análises experimentais de moagem em batelada de mesclas binárias em escala de laboratório, utilizando-se os minerais dolomita e quartzo.

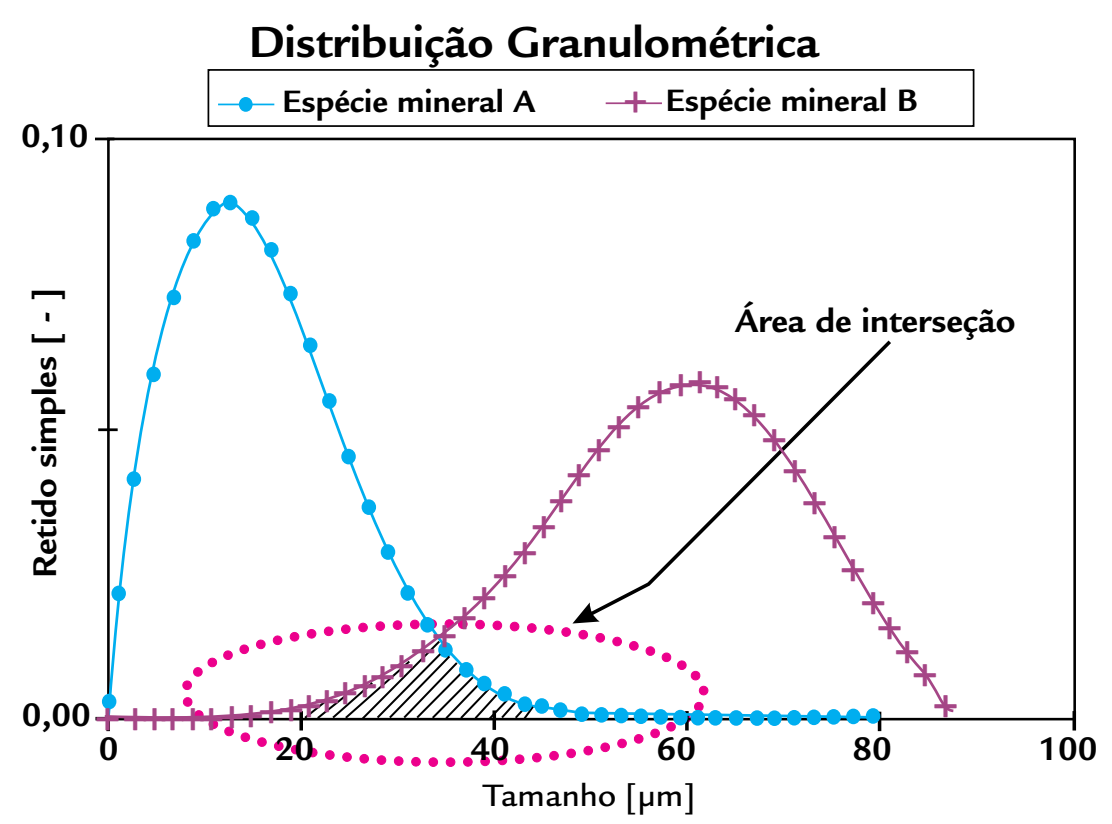

Figura 1

Distribuições granulométricas hipotéticas das frações retidas simples de duas espécies minerais, $A$ e $B$, produtos de um minério binário.

\section{Revisão da literatura}

A moagem encerra o último estágio do processo de fragmentação de minérios, para alcançar o tamanho especificado para alguma aplicação, ou até atingir o necessário grau de liberação dos componentes. A malha ideal de moagem depende de cada minério, distribuição do mineral útil na ganga, processos de separação subsequentes e outros fatores (Luz et alii, 2004), além da priorização de maior separabilidade dos minerais constituintes em cada etapa de moagem e melhor aproveitamento energético nos processos de tratamento.

Uma dos parâmetros mais utilizados no estudo de cominuição mineral é a moabilidade, compreendida como resistência à cominuição em moinhos, dependendo, basicamente, da variedade de minerais que constituem o minério considerado, de suas proporções (Turgut \& Arol, 1996), além do grau de redução das partículas (Wills \& Napier-Munn, 2006; Stamboliadis, 2007). Deve-se levar em conta que um material pode ser fraturado com certa facilidade (por destacamento de grãos) até determinado limite granulométrico, mas com maior dificuldade, a partir desse limite (devido à quebra intragranular), diminuindo-se a moabilidade (Wills \& Napier-Munn, 2006).

Com relação ao consumo energético na moagem, de forma pessimista, acreditava-se que sua eficiência energética não chegava a $1 \%$ (Wills \& Napier-Munn, 2006) e, de forma um pouco otimista, que não alcançava a margem dos $3 \%$ (Austin apud Lynch, 1977), em relação à geração de novas áreas superficiais. Estudo recente, por meio de nova metodologia, porém, advoga que o aproveitamento energético na moagem localiza-se, tipicamente, em torno de 8 a $23 \%$, dependendo do material sólido cominuído (Tavares, 2003).

Mesmo assumindo essa nova quantificação, o aproveitamento energético na moagem é baixo e o estudo de soluções que tornem mais eficiente essa operação é de fundamental importância para a indústria, pois tais soluções culminam em redução de custos de operação, aumento da margem de lucro e diminuição da demanda energética.

Com a finalidade de estimar o consumo em termos energéticos na moagem, uma expressão muito conhecida é a de Bond. Trata-se de lei empírica que considera que a energia consumida na cominuição é proporcional ao comprimento das fissuras iniciais que se desencadeiam 
no fraturamento (Beraldo, 1987). A Lei de

Wé a energia aplicada [J/kg]; $W_{i}$ é o índice de trabalho, característico do material submetido à cominuição e do processo. Esse índice representa a energia específica necessária à sua redu-

Onde $P^{*}$ é um tamanho (em $\mu \mathrm{m}$ ), dependente do processo e do material, tal que, se $P=P^{*}$, vale lei de Bond. Essa equação tem sido preconizada em especial para etapas de britagem.

Convergindo a atenção para a moagem mista (de dois componentes), justifica-se a preocupação de compreender a importância dos diversos fatores ligados à alimentação do sistema e aos parâmetros de operação de moagem, visando-se a criar soluções que possam maximizar a eficiência energética na cominuição e a eficiência de separação subsequente.

Bozkurt e Özgür (2007) estudaram a taxa específica de quebra da colemanita na moagem a seco em comparação ao quartzo e concluíram que a colematita é cominuída muito mais rapidamente do que o quartzo (devido à maior moabilidade da primeira), produzindo grande quantidade de finos. Nesse caso, o estudo da cominuição conjunta desses dois minerais sugeriu que se fizesse uma classificação, em determinada altura do processo, para se evitar a sobremoagem da colemanita.

De acordo com Ray e Szekely (1973), pesquisas realizadas focadas no estudo de moagem e mesclas binárias de componentes minerais em moinho de bolas mostraram que a eficiência da moagem é diminuída,

Onde:

$Y_{i}$ : fração do material na classe granulométrica $i[-]$.

$x_{i}$ : diâmetro da classe $i[\mathrm{~m}]$.

\section{Materiais e métodos}

Para a realização dos experimentos de moagem de mesclas binárias escolhe-
Bond se tornou muito popular e passou a

ser escrita da seguinte forma: ção de granulação de diâmetro infinito a outra com $80 \%$ passante na malha de 100 micrômetros [J/kg]; sendo P e A os diâmetros $[\mu \mathrm{m}]$, nos quais passam $80 \%$ da massa, respectivamente, do produ- to e da alimentação. Uma variante da equação de Bond tem sido proposta por Magdalinovic (Jankovic e colaboradores, 2004), equação esta que também se pode expressar por:

$W=10 \times W_{i} \times \sqrt{\frac{P^{*}}{P}} \times\left(\frac{1}{\sqrt{P}}-\frac{1}{\sqrt{A}}\right)$

uma vez que se constatou que a taxa de moagem de cada mineral decresceu em comparação aos resultados da moagem alimentada com estes mesmos componentes isoladamente. Essa conclusão se baseou no estudo da moagem composta pelos minerais calcita e quartzo. Outros minerais foram objetos de estudo, como arenito, dolomita e calcário, os quais foram moídos, demonstrando que o mesmo fenômeno ocorreu também nesses casos.

Tanaka (apud Ray \& Szekely, 1973), realizando experimentos com minerais de granulação muito fina, não confirmou tal fenômeno. Porém observou que, para tamanhos muito pequenos de partículas, a relação foi cíclica, onde no intervalo de 5 a $30 \mu \mathrm{m}$, perceberam-se de dois a quatro ciclos de alternância da magnitude dos valores de granulação final. Por meio desse estudo, notou-se, também, a existência de proporcionalidade entre relação de resistência e o número de ciclos. Sudário e Luz (2009) têm estudado a moagem de misturas binárias de quartzo com calcita, visando ao desenvolvimento de algoritmo de otimização algébrica para cominuição de misturas binárias.

Outro exemplo de estudo de moagem mista foi realizado por Sener e colaboradores (2003), que testaram o efeito do aqueci-

$$
Y_{i}=\frac{x_{i}^{a}}{x_{i}^{a}+d_{50}^{a}}
$$

mento (de $573 \mathrm{~K}$ a $1173 \mathrm{~K}$ ) sobre mistura composta por celestita e gipsita, objetivando atingir a máxima separação dos componentes, decorrente da calcinação do segundo mineral. Confirmou-se um aumento na moabilidade da gipsita. Isso contribuiu para uma separação mais eficiente entre as espécies minerais, possibilitando o beneficiamento do minério estudado, usando-o em um único estágio de separação.

A descrição de distribuições granulométricas de particulados em equipamentos de processos por distribuição probabilística é procedimento clássico. As funções de distribuição de probabilidade de RosinRammler, de Meloy-Gaudin, de Harris e de Gates-Gaudin-Schuhmann são muito utilizadas para predizer a distribuição granulométrica e para calcular o tamanho $d_{50}$ ou $d_{80}$, comumente utilizados para caracterizar a finura dos produtos do moinho (Stamboliadis, 2007).

Uma função de distribuição de probabilidades muito simples, denominada sigmóide de Hill, foi utilizada com sucesso para representação de curvas de sedimentação (Luz, 2005), além de representação de distribuição granulométrica de sistemas particulados genéricos (Luz, 2009).

A Sigmoidal de Hill tem a seguinte expressão:

a: coeficiente de agudez [-].

$d_{50}$ : diâmetro mediano da distribuição $[\mu \mathrm{m}]$.

A vantagem de utilização dessa função reside nas fáceis integrabilidade e diferenciabilidade em qualquer ponto. ram-se dois minerais de moabilidades diferentes. Os minerais escolhidos foram:
- Dolomita (formação Gandarela do super-grupo Minas, $W_{i}=45,36 \mathrm{~kJ} /$ 
(a)

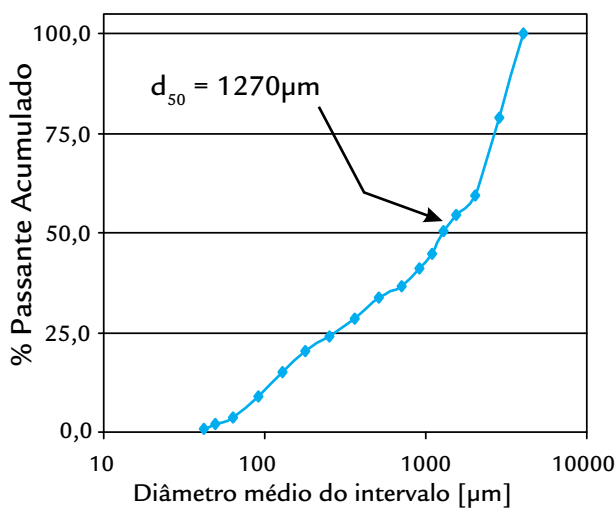

$\mathrm{kg}$ ): originalmente na granulometria de brita zero, mineral fornecido pela empresa Bemil Beneficiamento de Minérios Ltda., em Ouro Preto, MG.

- Quartzo (originalmente na forma de blocos centimétricos, $W_{i} \cong 51,84 \mathrm{~kJ} / \mathrm{kg}$ ), obtido na própria região de Ouro Preto.

Na campanha experimental, realizaram-se ensaios de moagem a seco, fazendose uso de diferentes proporções volumétricas dos minerais Os resultados foram ajustados pela função de distribuição de probabilidades, sigmóide de Hill, tomando os parâmetros agudez, $a$, e tamanho $d_{50}$ das distribuições granulométricas (maiores detalhes podem ser vistos em Rosa, 2009). (b)

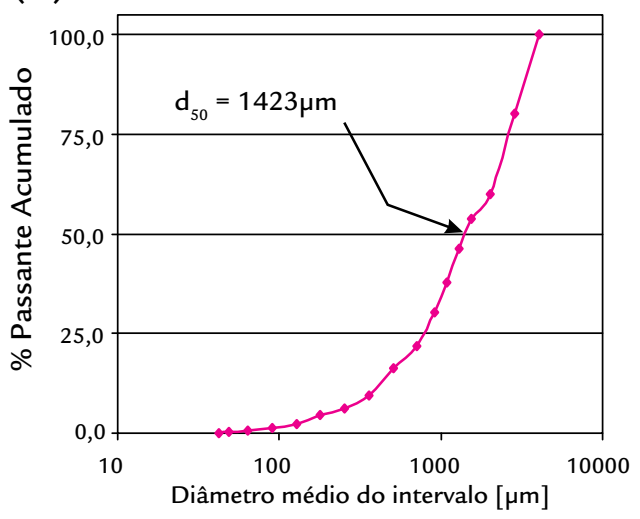

Análise comparativa prévia da aderência regressional da sigmoidal de Hill com a de Rosin-Rammler mostrou desempenho muito parecido, o que justificou, plenamente, a seleção da função de Hill, tendo em vista futuras comparações com sistema de otimização algébrica de moagem de sistemas binários, em desenvolvimento paralelo a esse trabalho (Sudário \& Luz, 2009).

Partindo-se de massas de aproximadamente $100 \mathrm{~kg}$ de cada mineral, as mesmas foram reduzidas em $100 \%$ passantes na peneira de $3,35 \mathrm{~mm}$, para compor a alimentação do moinho.

As massas cominuídas foram homo-
Figura 2

Distribuições granulométricas dos minerais: (a) dolomita e (b) quartzo, utilizados na alimentação da moagem binária mista, destacando-se os respectivos diâmetros $\mathrm{d}_{50}$.

geneizadas pelo método de pilhas cônicas e, na sequência, por pilhas longitudinais. Da pilha longitudinal de cada mineral, foram retiradas duas amostras para caracterizar a granulometria da alimentação. As análises granulométricas foram feitas por peneiramento e o cálculo das massas de cada componente da alimentação foi feito na sequência de peneiras da série ABNT (de $2380 \mu \mathrm{m}$ a $44 \mu \mathrm{m}$ ). As distribuições das alimentações vêem-se na Figura 2 (nota-se que as abscissas das curvas granulométricas, no presente artigo, referem-se ao diâmetro médio aritmético de cada classe granulométrica dada por peneiras contíguas).

\section{Ensaios de moagens de mesclas binárias}

Para a realização das moagens das mesclas binárias, foi usado moinho tubular tipo jarro, revestido, internamente, de borracha, cujas dimensões efetivas são 0,195 m (diâmetro) e 0,195 m (comprimento), encerrando volume total de 5,824 litros. A moagem foi realizada a uma velocidade angular de $59 \mathrm{rpm}$, com carga fixa de bolas e minério, com ocupação de $46 \%$ do volume do moinho. A carga de bolas foi estabelecida segundo os tamanhos descritos na Tabela 1.

Os ensaios de moagem totalizaram 25 experimentos, variando-se a proporção na mescla dos minerais dolomita e quartzo, mantendo-se o volume total de minério fixado em $1560 \mathrm{~cm}^{3}$.

As proporções em volume das mesclas minerais foram feitas da seguinte maneira: $25 \%$ de dolomita e $75 \%$ de quartzo; $50 \%$ de dolomita e $50 \%$ de quartzo; e, finalmente, de $75 \%$ de dolomita e $25 \%$ de quartzo. Para todas as mesclas, foram realizadas moagens nos ciclos de tempo de 5, 15, 30, 50 e 75 minutos. Também foram realizadas moagens isoladas das espécies minerais, para os mesmos ciclos de tempo.

Para determinar a massa a ser cominuída em cada experimento, era utilizada proveta graduada de dois litros, onde cada mineral era adicionado separadamente dentro da mesma até ser completado o volume desejado para cada ensaio. Em seguida, o material, na proveta, era compactado sobre mesa vibratória, durante $120 \mathrm{~s}$. Tendo havido compactação de volume, o mesmo era

\begin{tabular}{c|c|c|c}
\hline Tamanho $[\mathrm{mm}]$ & Quantidade & Massa total $[\mathrm{kg}]$ & Proporção [\%] \\
\hline 39.5 & 14 & 3.6 & 40.3 \\
\hline 30 & 31 & 3.6 & 40.5 \\
\hline 17 & 87 & 1.71 & 19.2 \\
\hline Total & 132 & $\mathbf{8 . 9 2}$ & 100 \\
\hline
\end{tabular}

completado e o procedimento de compactação se repetia até não haver mais variação volumétrica, definindo-se a massa do mineral nesse instante. Esse procedimento era efetuado em triplicata, para cada proporção de mescla, adotando-se a média aritmética.

As amostras eram adicionadas no moinho, já com a carga de bolas na proporção definida para cada teste. Após o tempo de moagem definido, o produto era retirado do moinho e, após homogeneização em lona, quarteado, utilizando divisor Jones, até a obtenção de duas alíquotas para análise granulométrica de, aproximadamente, $0,350 \mathrm{~kg}$ cada uma. Para o caso de moagem das mesclas, o retido em cada peneira era pesado e enviado para análise de teor.

Tabela 1

Distribuição de bolas utilizadas como corpos moedores nos ensaios de moagem mista binária. 


\section{Determinação das massas de dolomita e quartzo no produto}

O teor de dolomita presente na amostra foi determinado por curvas de calibração confeccionadas a partir de experimentos controlados de calcinação para massas fixas de minério. Para isso, amostras preparadas de granulação predominantemente fina, de $5 \mathrm{~g}$ e $30 \mathrm{~g}$, e contendo diferentes proporções preestabelecidas dos minerais dolomita e quartzo, foram calcinadas por uma hora em mufla, cuja temperatura foi ajustada em $1.373 \mathrm{~K}$

\section{Resultados e discussão}

A Figura 3 compara a evolução da

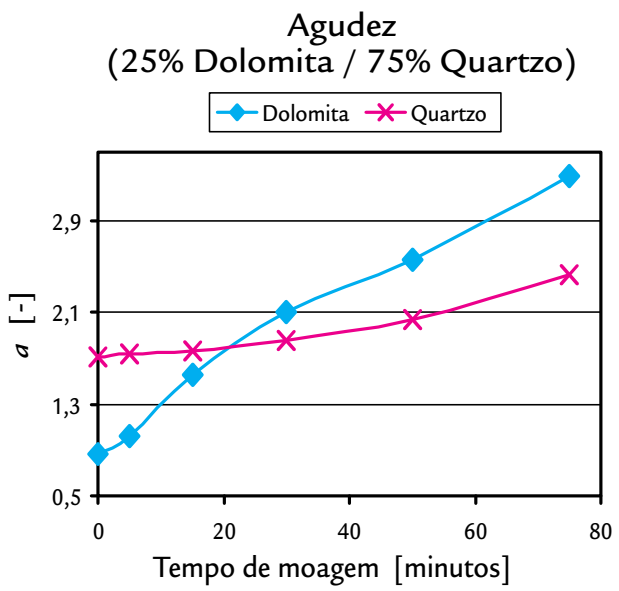

(25\% Dolomita $\mathrm{d}_{50}$ 75\% Quartzo)

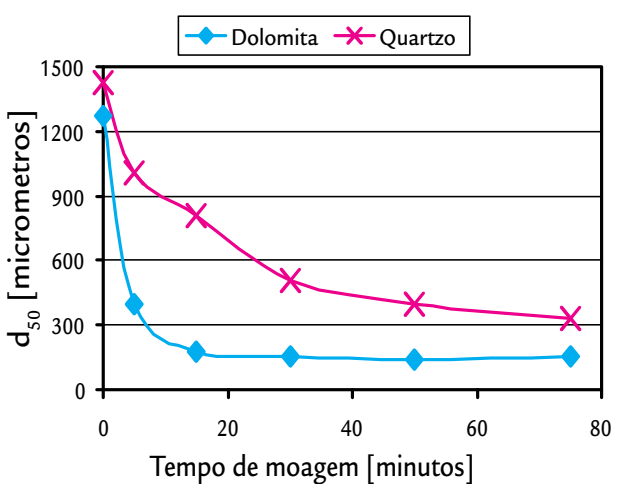

Agudez

(75\% Dolomita / 25\% Quartzo)

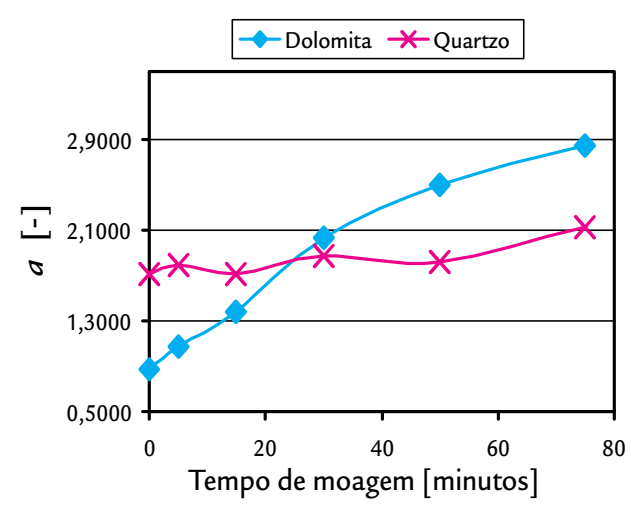

$\left(1.100^{\circ} \mathrm{C}\right)$. As calcinas eram resfriadas e pesadas, obtendo-se as perdas de massa atribuídas à evolução de $\mathrm{CO}_{2}$. Obteve-se correlação positiva perfeita entre a perda de massa $(\mathrm{P})$ em gramas e o teor percentual de dolomita (Y), a saber:

- Amostra inicial de $5 \mathrm{~g}$ :

$\mathrm{Y}=44,11 \times \mathrm{P}$.

- Amostra inicial de $30 \mathrm{~g}$ :

$\mathrm{Y}=7,31 \times \mathrm{P}$.

Mediante os resultados, os per- centuais de massa passante acumulados de cada mineral foram determinados, obtendo-se o tamanho $d_{50}$ de cada distribuição, bem como coeficiente de agudez a, tendo sido este determinado através do ajuste dos dados à função distribuição de probabilidade de Hill, utilizando-se, para tanto, o programa EasyPlot ${ }^{\circledR}$ da Spiral Software. Para todos os ajustes, obtiveram-se excelentes aderências (correlações mínimas de 97 \%).

agudez, $a$, e do diâmetro, $d_{50}$, dos proAgudez (50\% Dolomita / 50\% Quartzo)

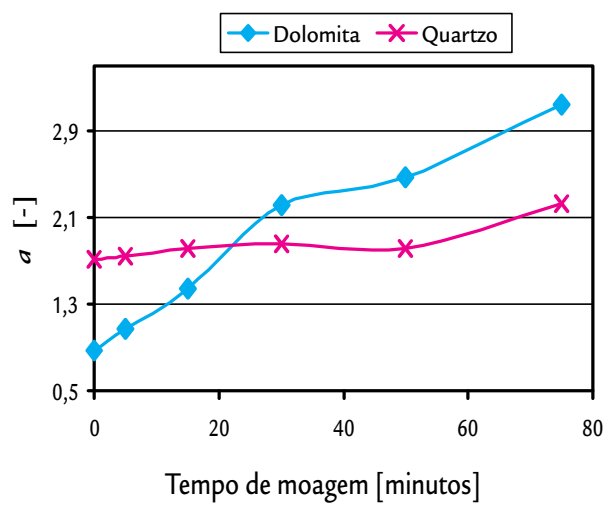
(50\% Dolomita / $50 \%$ Quartzo)

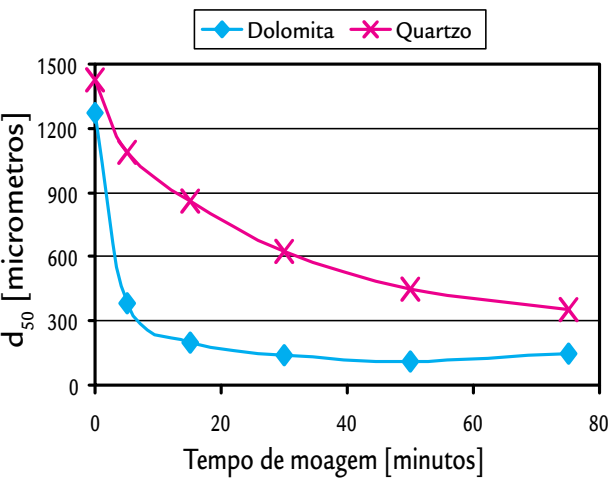
(75\% Dolomita / 25\% Quartzo)

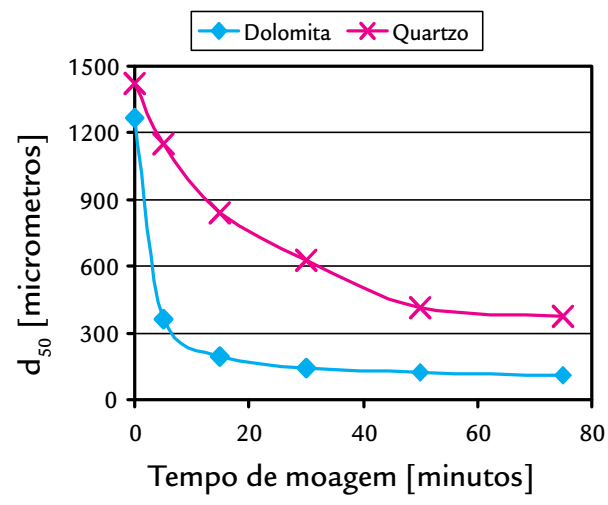

dutos da moagem, segundo os padrões
Figura 3

Evolução da agudez e d50 dos produtos nas mesclas. 
ensaiados. Pode-se perceber que, conforme evoluiu o tempo de moagem, os coeficientes de agudez aumentaram para ambas as espécies minerais, diminuindo,

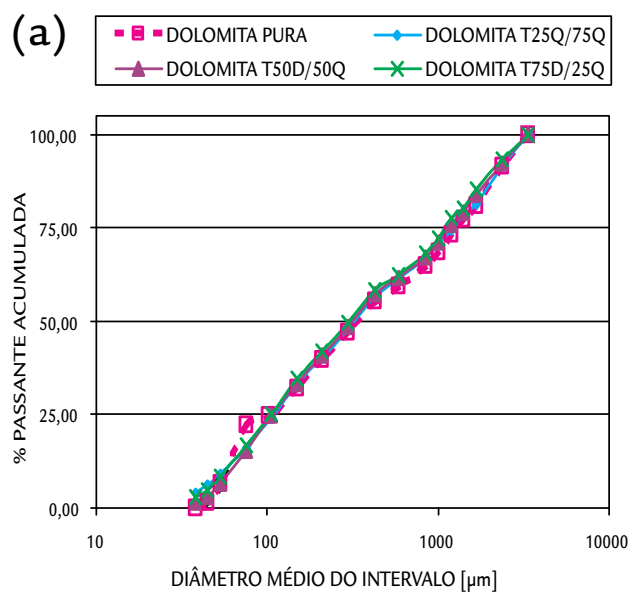

(c)
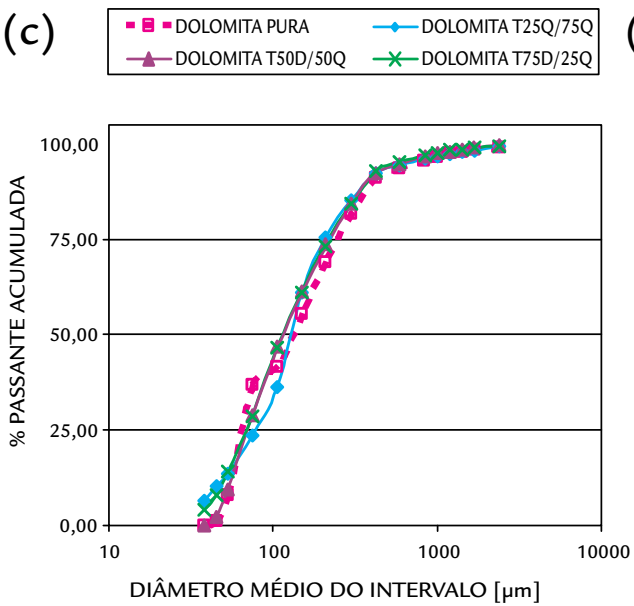

mentais usando-se a distribuição clássica de Rosin-Rammler-Sperling-Benett (caso especial da distribuição de Weibull) também foi testada (bem como as de Gaudin-Meloy e Gaudin-Schumann), sem ganhos significativos no coeficiente de correlação.

As Figuras 4 e 5 mostram, compa- (d)
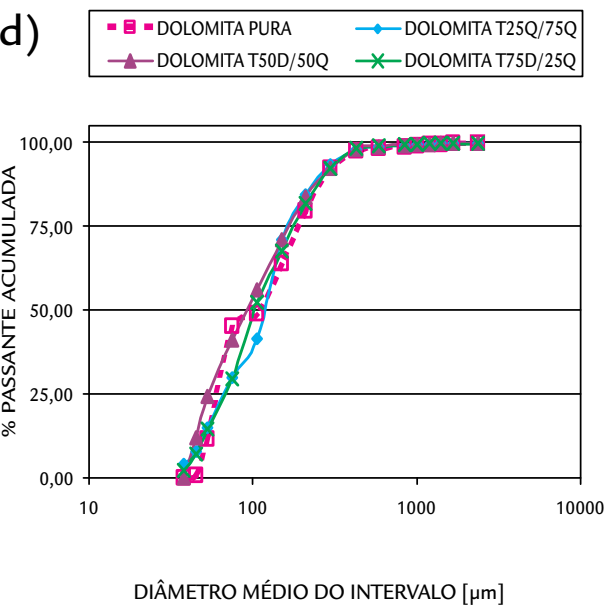

(e)
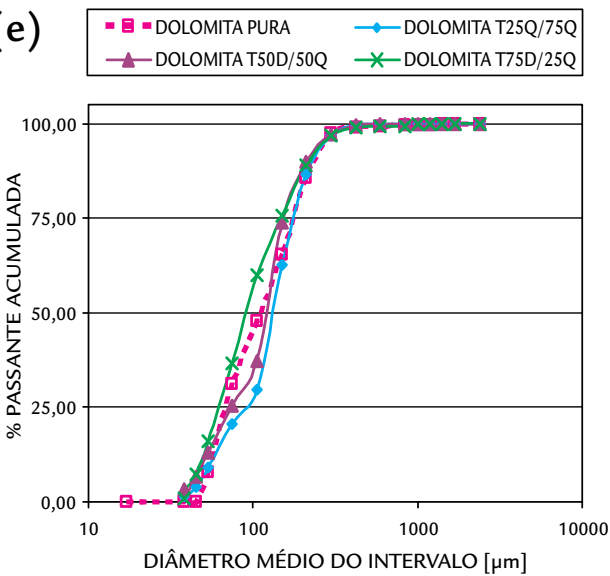

por consequência, a dispersão das curvas de distribuições de suas frações retidas. Por outro lado, o diâmetro, $d_{50}$, diminuiu conforme $a$ evoluiu o tempo de moagem,
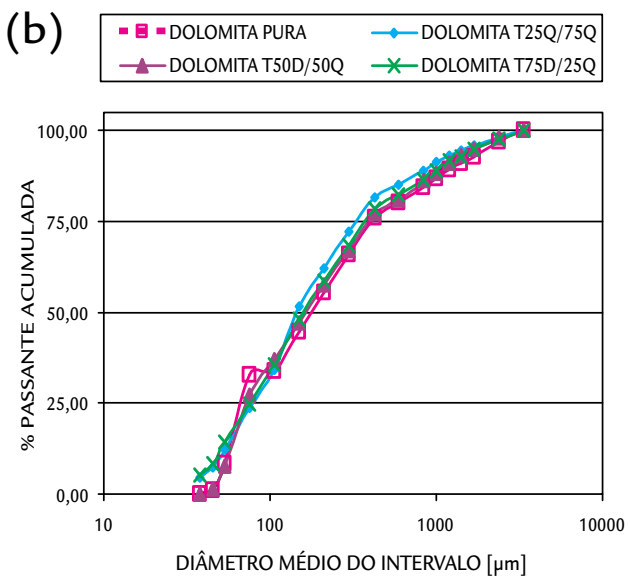

DIÂMETRO MÉDIO DO INTERVALO [ $\mu \mathrm{m}]$

rativamente, o comportamento granulométrico dos minerais dolomita e quartzo nas moagens mescladas em relação as suas respectivas moagens isoladas, segundo os mesmos ciclos de tempo. Observa-se que, à exceção do tempo de 5 minutos, a moagem mesclada do quartzo apresentou-se mais grosseira em relação proporcionando maior proximidade entre os centros das distribuições das frações retidas dos minerais.

A correlação das nuvens experi-
Figura 4

Granulometria do quartzo após moagem: (a) 5 minutos, (b) 15 minutos, (c) 30 minutos, (d) 50 minutos e (e) 75 minutos.

a sua moagem isolada. Tratando-se de dolomita, no geral, não se percebem grandes discrepâncias, a menos nos ciclos de moagem de 5 e 15 minutos. Ao contrário do que ocorreu para o quartzo, a moagem mista apresentou-se mais fina em relação as suas respectivas moagens isoladas. 

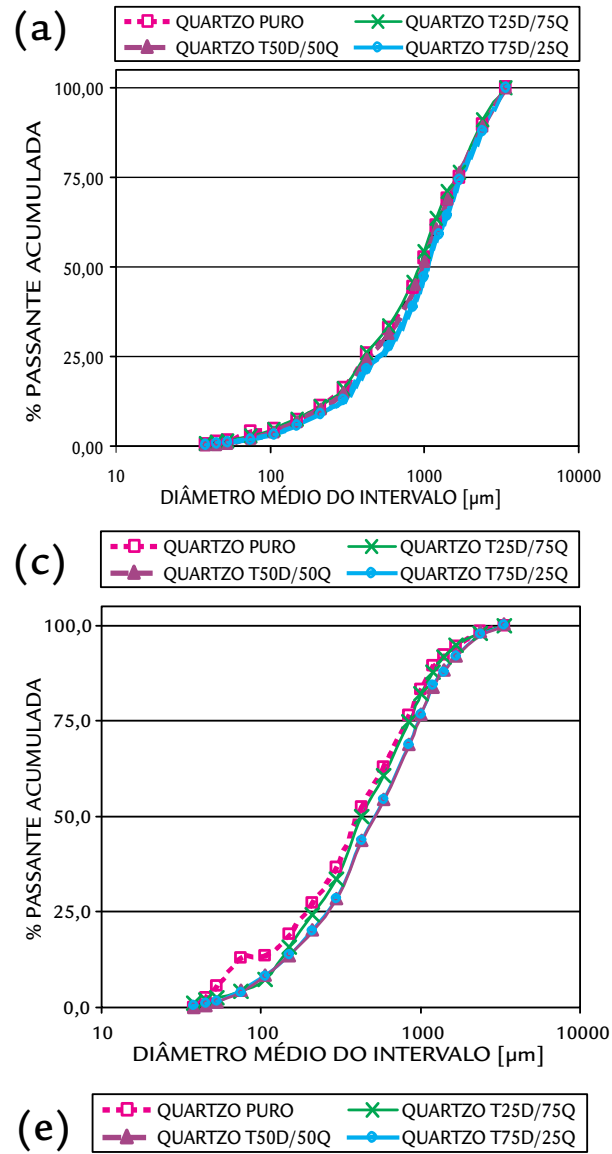

Figura 5

Granulometria da dolomita após moagem: (a) 5 minutos, (b) 15 minutos, (c) 30 minutos, (d) 50 minutos e (e) 75 minutos.

\section{Conclusão}

Os resultados provaram que a dolomita é cominuída mais rapidamente em comparação ao quartzo nas suas moagens mescladas. A razão para esse fato pode ser explicada pela maior moabilidade do mineral dolomita, cujos finos gerados, no início da moagem, diminuem de forma significativa o efeito de impacto da carga de bolas sobre o mineral de

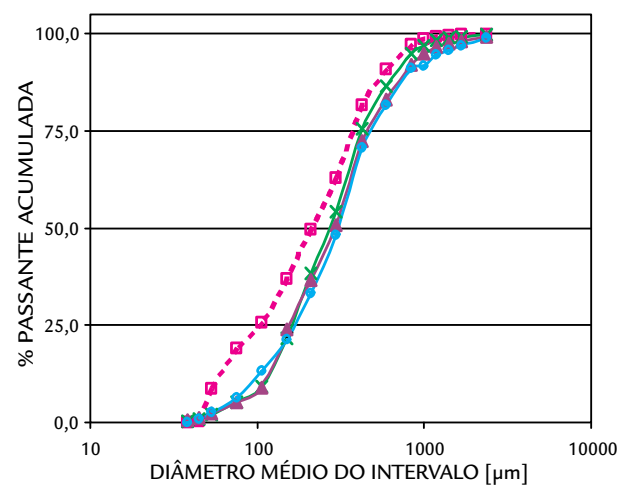

menor moabilidade, o quartzo.

O diâmetro, $d_{50}$, diminuiu, enquanto a agudez, $a$, aumentou com o progresso da moagem, uma vez que, inicialmente, não se tinha sistema bitolado (correspondente à agudez elevada).

A partir dos resultados desse trabalho, foi desenvolvido simulador de cominuição baseado em rede neural

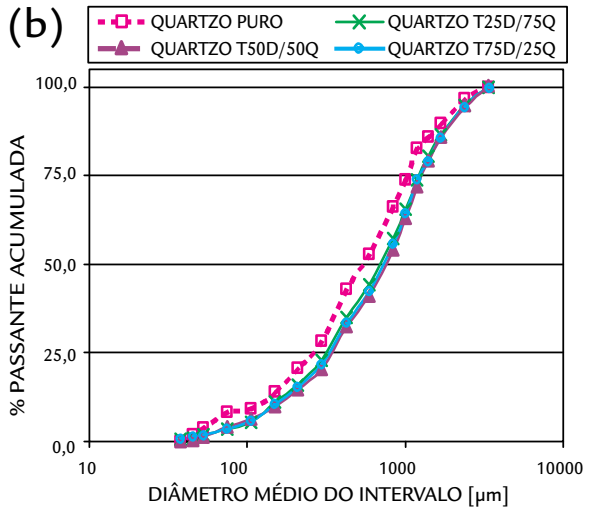

(d) - - - QUARTZO PURO $*$-QUARTZO T25D/75Q

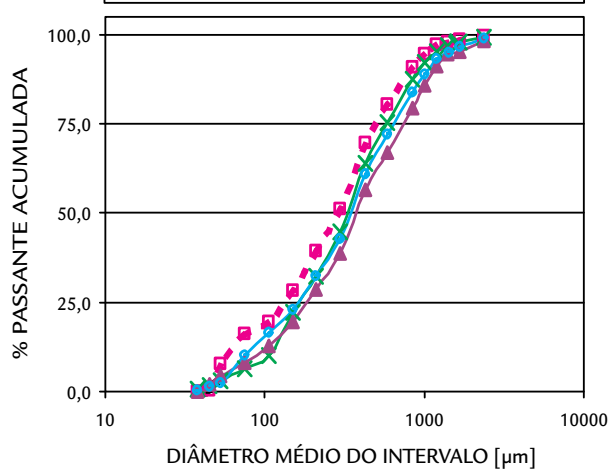

DIÂMETRO MÉDIO DO INTERVALO [ $[\mu \mathrm{m}]$ artificial, do tipo perceptron de multicamada, com algoritmo de supervisão e treinamento baseado em retropropagação com momento.

Tal sistema já foi validado e mostrou-se eficaz na previsão do desempenho da moagem de misturas binárias e será objeto de artigo futuro, em continuidade a esta pesquisa.

\section{Referências bibliográficas}

BERALDO, J. L. Moagem de minérios em moinhos tubulares. São Paulo: Edgard Blücher, 1987. $143 \mathrm{p}$.

BOZKURT, V., ÖZGÜR, I. Dry grinding kinetics of colemanite. Powder Tecnology. Turkey, v. 176, n. 2, p.88-92, July 2007.

CHAVES, A. P., PERES, A. E. C. Teoria e prática do tratamento de minérios: britagem, peneiramento e moagem. São Paulo: Signus Editora, 1999. 238 p.

DELBONI JUNIOR, H. Cominuição. In: FERNANDES, F. R. C. et alii (Ed.). Tendências tec- 
nológicas Brasil 2015: geociências e tecnologia mineral. Rio de Janeiro: CETEM/MCT, 2007. p. 103-131.

LUZ, A. B. da et alii. Tratamento de minérios. Rio de Janeiro: CETEM/MCT, 2004. 858 p.

LUZ, J. A. M. da. Aspectos reológicos de polpas em sedimentação. In: CIMINELLI, R. R. et alii (Ed.). In: CONGRESSO DA ABM, 64. Anais... São Paulo: ABM, 2009. p. 1-11. CD ROM.

LUZ, J. A. M. da. Fracionamento granulométrico de sistemas particulados. Ouro Preto: UFOP, 2009. 120 p. (Notas de Aula).

LYNCH, A. J. Mineral crushing and grinding circuits: their simulation, optimization, design and control. Amsterdam: Elsevier, 1977. 354 p.

RAY, W. H.7\& SZEKELY, J. Process Optimization: with applications in metallurgy and chemical engineering. New York: Wiley \& Sons, 1973. 371 p.

ROSA, G. M. Cominuição seletiva de mesclas binárias e sua simulação por redes neurais artificiais. Ouro Preto: UFOP, 2009. 183 p. (Dissertação de Mestrado).

SENER, S. et alii. Effect of heat treatment on grindabilities of celestite and gypsum and separation of heated mixture by differential grinding. Minerals Engineering, v. 17, n.3, p.473475, Mar 2004.

STAMBOLIADIS, E. T. The energy distribution theory of comminution specific surface energy, mill efficiency and distribution mode. Minerals Engineering, v. 20, n. 2, p.140-145, Feb 2007.

SUDÁRIO, F. E., LUZ, J. A. M. da. Cominuição seletiva de misturas binárias. In: BRUM, I. A. S. et alii (ed.).ENTMME. 23. Anais... Porto Alegre: UFRGS, 2009. v. 2. p. 247-254.

TAVARES, L. M. Um novo método para o cálculo da eficiência energética de moinhos industriais. 2003. Disponível em: <http://www.materia.coppe.ufrj.br/mirror/sarra/artigos/ artigo10093/index.html> . Acesso em 22/09/2007.

TURGUT, C., AROL, A. I. Grinding behaviours of minerals mixtures. In: KEMAL, M. et alii (Ed.). Changing Scopes in Mineral Processing. Rotterdam: A. A. Balkema, 1996. pp. 9-14.

WILLS, B. A., NAPIER-MUNN. T. Wills' mineral processing technology: an introduction to the practical aspects of ore treatment and mineral recovery (7. ed.). Oxford: ButterworthHeinemann - Elsevier, 2006. 444 p.

Artigo recebido em 10 de janeiro de 2010. Aprovado em 22 de abril de 2010. 